\title{
Small-Town Martyrs and Murderers, Religious Revolution and Counterrevolution in Western
} France

Jean-Clément Martin

\section{(2) OpenEdition Journals}

Édition électronique

URL : https://journals.openedition.org/ahrf/8013

DOI : 10.4000/ahrf.8013

ISSN : 1952-403X

Éditeur :

Armand Colin, Société des études robespierristes

Édition imprimée

Date de publication : 1 décembre 2006

Pagination : 188-190

ISSN : 0003-4436

\section{Référence électronique}

Jean-Clément Martin, «Small-Town Martyrs and Murderers, Religious Revolution and Counterrevolution in Western France », Annales historiques de la Révolution française [En ligne], 346 | Octobre/Décembre 2006, mis en ligne le 10 juillet 2008, consulté le 24 avril 2022. URL : http:// journals.openedition.org/ahrf/8013; DOI : https://doi.org/10.4000/ahrf.8013

Ce document a été généré automatiquement le 24 avril 2022.

Tous droits réservés 


\section{Small-Town Martyrs and Murderers, Religious Revolution and Counterrevolution in Western France}

Jean-Clément Martin

\section{RÉFÉRENCE}

Edward J. Woell, Small-Town Martyrs and Murderers, Religious Revolution and Counterrevolution in Western France, 1774-1914, Milwaukee (Winsconsin), Marquette University Press, 2006, 292 p., ISBN 0-87462-311-1, 32 \$.

1 Tiré d'une thèse, ce livre est consacré à l'histoire d'une commune particulièrement célèbre dans les guerres civiles qui ont ravagé l'ouest de la France entre 1793 et 1832, Machecoul, qui se situe $25 \mathrm{~km}$ au sud-ouest de Nantes. Les «massacres» qui s'y sont commis pendant le printemps de 1793 ont radicalisé l'opposition nationale à la contrerévolution. Des chiffres apocalyptiques furent avancés, puis repris souvent pendant les deux siècles qui suivirent. L'étude de E. J. Woell insère cet événement dans une histoire longue, en commençant dans les années 1770 et en l'achevant au moment de la première guerre mondiale.

2 Le projet est louable ; le livre, agréable à lire, est fondé sur des archives tant laïques que religieuses, et sur l'historiographie. La démarche est sans surprise. Le premier chapitre décrit les structures sociales et religieuses de la commune, insistant sur l'apparente cohésion communautaire, rompue par des divisions semblant peu profondes autour du jansénisme et des pratiques variées face à l'observation des règles édictées par le clergé. Mais tous les paroissiens sont catholiques et il est vain de chercher parmi eux des ruptures nettes comme Tilly avait pu le mettre en avant dans les Mauges ou Bois dans la Sarthe. Reste que les pratiques des hommes et des femmes sont différentes, que 
les artisans et les ruraux se séparent également; soit autant de clivages fins qui traversent la sociabilité communautaire dans les églises et les écoles. Ces failles jouent brutalement avec les conséquences de la Révolution et l'introduction de la Constitution civile du clergé : d'un seul coup les oppositions s'affirment à propos de l'application des lois. Dans un schéma dorénavant bien établi, les tensions de 1791 mettent face-à-face notables et mécontents, rompent les familles autant que les groupes sociaux. La radicalisation se fait en 1792 autour des nobles et des curés, les moindres incidents (une jeune fille à cheval à l'attitude arrogante) deviennent des occasions d'affrontements. Reste que ces manifestations attestent que des chrétiens bleus, comme Michel Lagrée l'avait bien vu en Bretagne, existent et représentent une force non négligeable. Le passage à la violence la plus grande se fait naturellement en 1793 sous la pression des demandes de la République. Dans ces massacres, la religion a joué un rôle essentiel, mais complexe, servant de cadre explicatif, permettant la cristallisation des opinions, comme la vulgarisation d'une culture du sacrifice.

3 Les conséquences immédiates changent la compréhension des événements puisque l'importance des violences fait oublier cette naissance conjoncturelle de 1793 pour leur donner une allure clairement sacrificielle en 1794: il s'agit là d'un point particulièrement neuf apporté par le livre. Sur cette base, les croyances deviennent plus déterminantes que la réalité des faits, si bien que deux narrations se bâtissent aussitôt rendant difficile la reconstruction de la paix dans la communauté. Logiquement, cette situation débouche sur la durabilité des discours militants qui façonnent la société machecoulaise pendant le siècle suivant. L'église est le pivot autour duquel les rappels du bonheur de l'Ancien Régime, les souvenirs des martyrs sont à la base des engagements dans les fêtes locales, dans les associations (y compris sportives), bien entendu dans les luttes politiques, notamment en 1832 quand la duchesse de Berry tente de soulever la région, ou quand les zouaves pontificaux partent défendre le Saint-Siège, enfin au moment de la querelle des inventaires. L'auteur décrit cependant une prolongation nuancée, rappelant l'effritement progressif des attitudes, la conciliation avec le siècle dans les dernières années. Machecoul est ainsi exemplaire d'une situation déjà explorée.

4 Le livre pourtant laisse sur sa faim pour plusieurs raisons. Quelques erreurs peuvent être relevées, comme celle qui fait arriver Hoche quelques mois trop tôt pour pacifier la région. Des ouvrages ne sont pas cités, inexplicablement, puisque les réfugiés, étudiés par P. Latteux puis par G. M. Lenne, auraient dû entrer dans la démonstration. Surtout on ne comprend pas pourquoi les Machecoulais commettent cette violence considérable. Le rappel des événements de 1791-1792 est lacunaire et ne permet pas de voir comment la violence ordinaire progresse, entre dans les habitudes et se généralise. Plutôt que de vouloir faire descendre l'ankou au sud de la Loire, en invoquant de prétendues pratiques superstitieuses, il aurait été profitable de montrer comment les communes proches avaient été marquées par des affrontements parfois mortels, mobilisant les individus et les accoutumant à la mort. Il y a eu montée des affrontements, tueries réciproques, les meurtres de 1793 en sont la conséquence. Si les deux narrations qui en découlent sont certes une excellente idée, l'exploitation demeure faible. Pourquoi la narration républicaine disparaît-elle? L'exploitation des massacres de Machecoul par les républicains (Michelet et Jaurès en sont de parfaits exemples) n'est pas exposée, elle était pourtant facilement accessible, y compris dans ses avatars sous la IIIe République quand un tableau monumental en rappela le souvenir d'une façon provocante. Le mutisme de l'auteur est gênant dans la mesure où 
donnant une grande place à la contre-révolution, il en oublie la puissance du courant républicain militant, à la fois localement et régionalement. Il n'y a jamais eu une seule mobilisation mais bien deux, qui ont trouvé leur sens dans la violence de 1793 qui a transfiguré des distinctions sociales qui n'avaient pas pris une ampleur considérable. Le livre incite ainsi à revoir les processus locaux qui ont fait basculer les communautés sous l'effet des lois, il conduit à comprendre que l'événement révolutionnaire a bien rompu les liens sociaux et a bien radicalisé des écarts, il montre bien comment ces événements font naître des traditions ; il n'a pas pourtant pris toutes les précautions nécessaires pour mettre en lumière tous les mécanismes, laissant penser que des déterminismes sont toujours à découvrir quand il $\mathrm{y}$ a eu, à l'évidence, des accumulations lentes de décalages et des glissements progressifs. 